\title{
AUTOPSY FINDINGS OF DICEPHALIC DIBRACHIUS PARAPAGUS CONJOINED TWINS: A CASE REPORT
}

Ato Ampomah Brown *1, Leonard Derkyi-Kwarteng ${ }^{2}$, Emmanuel Okai ${ }^{3}$, Kafui Akakpo ${ }^{2}$.

${ }^{* 1}$ Department of Anatomy, School of Medical Sciences, University of Cape Coast, Ghana.

${ }^{2}$ Department of Pathology, School of Medical Sciences, University of Cape Coast, Ghana.

${ }^{3}$ Department of Paediatrics, School of Medical Sciences, University of Cape Coast, Ghana.

\section{ABSTRACT}

This is a case report of a set of dicephalic parapagus twin delivered by caesarean section and who survived for 22 days postpartum. At autopsy each twin was found to have a separate upper gastrointestinal tract which eventually became shared in the mid gut region. Their vertebral columns ran side by side and also fused at the level of the lumbo-sacral region. Each twin possessed a pair of lungs but they shared a single fused heart. A complex cardiopulmonary system was identified which had the potential to support both twins.

KEY WORDS: Autopsy, Twins, Conjoined.

Address for Correspondence: AtoAmpomah Brown, University of Cape Coast, School of Medical Sciences, Department of Anatomy, Cape Coast, Ghana. Tel +233244648027

E-Mail: a.a.brown@uccsms.edu.gh

Access this Article online Quick Response code

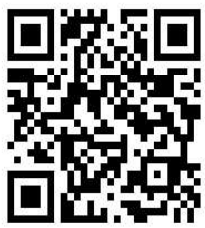

DOI: $10.16965 /$ ijar.2019.231

\begin{tabular}{l} 
ICV to \\
\hline \\
\hline$R$
\end{tabular}
Journal Information

International Journal of Anatomy and Research ICV for 2016 ISSN (E) 2321-4287 | ISSN (P) 2321-8967 90.30 https://www.ijmhr.org/ijar.htm DoI-Prefix: https://dx.doi.org/10.16965/ijar

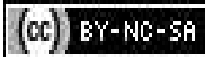

Article Information

Received: 25 May 2019

Peer Review: 25 May 2019

Revised: None
Accepted: 10 Jun 2019

Published (0): 05 Jul 2019

Published (P): 05 Jul 2019

\section{INTRODUCTION}

Conjoined twin is a rare phenomenon, with a worldwide prevalence of 1.47 per 100,000 births [1]. Dicephalic parapagus conjoined twins are fused laterally, have two distinct heads and share a pelvis [2,3]. Depending on the number of upper limbs present, they are referred to as dibrachius (two arms), tribrachius (three arms) or tetrabrachius (four arms). They make up less than $3 \%$ of all reported cases of conjoined twins and have a higher prevalence in males than in females [1].

\section{CASE REPORT}

In our case the mother was a 17 year old primigravida with no significant past medical history of note. Her antenatal clinic attendance was rather poor due to financial constraints. She had only two attendances with her booking visit at 18 weeks. All her routine antenatal blood tests including HIV, syphilis and hepatitis B were normal. She was Blood group $O$, rhesus positive. Our twins were delivered by emergency caesarean section in good condition and required minimal resuscitation. They were pink and well perfused with no signs of respiratory distress even though they had a resting respiratory rate of about 60-70cycles/minute. They were kept nil by mouth with hydration and energy requirements maintained by an intravenous infusion of $10 \%$ dextrose but this was changed on day 2 of life to milk as they persistently cried for feeds. Both of them had very good sucking and rooting reflexes and remained well until 
day 22 of life when they had a rapid deterioration in cardiopulmonary function and died within a few hours of showing signs of severe respiratory distress.

\section{Autopsy Findings}

External Examination: The conjoined twins were peripherally and centrally cyanosed. Both upper and lower limbs including fingers and toes were normal. They shared a single external female genitalia and a patent anus. Using a y incision, the organs were eviscerated en mass with exposure of a fused vertebral bodies at the level of the lumbo-sacral and coccygeal vertebrae. $A$ set of ribs were also observed running between and the thoracic vertebrae.

Fig. 1: Conjoined Twins.

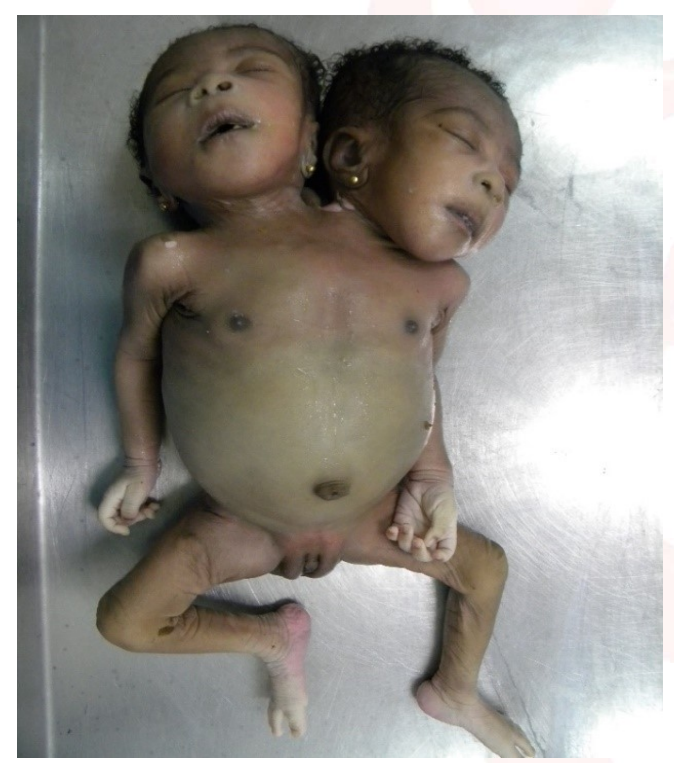

Fig. 2: Exposed thoracoabdominal cavity of conjoined twins showing fused lumbo-sacral and coccygeal vertebrae.

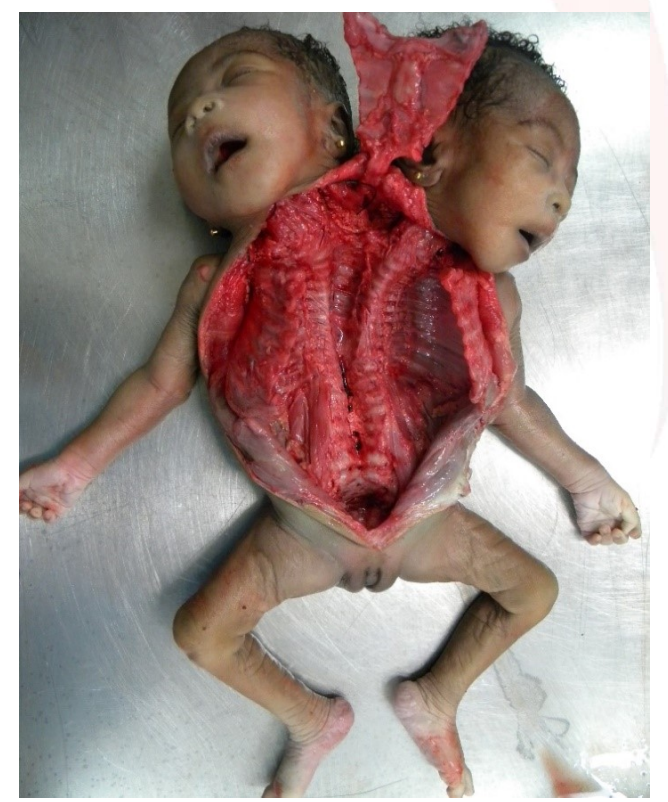

\section{Internal Examination}

Respiratory System: The larynx and bronchi were grossly normal. Each twin possessed a normal larynx, trachea and bronchi without fistulae or rings. Each twin had a pair of lungs. Twin one had 3 lobes on the left and 3 lobes on the right lung while twin two has 3 lobes on the right lung and 2 on the left.

Cardiovascular System: There was a single fused heart with a very complex anatomy. This consisted of two right atria separated by a septum, a common left atrium and common right and left ventricles which communicated via a ventricular septal defect. The superior and inferior vena cava, one from each twin emptied into their respective right atria, after which they emptied into a common right ventricle which in turn emptied into the lungs of twin two but not twin one. Twin one was found to have no pulmonary circulation. From the lungs, the pulmonary veins of twin two emptied into the common left atrium and subsequently into the shared left ventricle which finally emptied into two separate aortas. These aortas coursed down the posterior wall of the thorax and abdomen, with each aorta giving off a renal artery to the kidney closest to it. After which they fused into a common aorta and subsequently divided into the common iliac arteries as they approached the shared pelvis.

Gastrointestinal System: Two oesophaguses that emptied into two stomachs were observed. The small bowels continued from their respective stomachs as separate units until a point in the jejunum where they fused with a single lumen and the gastro-intestinal tract continued thereafter as a single unit and eventually ended at a single patent anus.

Hepatobilliary System: Two livers that were fused in the midline were observed, with each liver having its own gallbladder.

Lymphoreticular System: Two normally appearing spleens were observed. The hilar, retroperitoneal and intra-abdominal lymph nodes also appeared normal.

Genitourinary System: There were two kidneys with a single ureter emerging from each kidney both of which emptied into a single urinary bladder. 
Endocrine System: The pituitary gland and the parathyroid of each twin are unremarkable. Both adrenal glands are of normal size and shape and have grossly normal cut surfaces. The thyroid gland of each twin is grossly normal.

\section{DISCUSSION}

The live birth incidence of conjoined twin is one set in 200,000 live births $[4,5,6]$. This is a random event and unrelated to hereditary, maternal age and parity. The classic theory underpinning conjoined twinning is the incomplete separation of a single embryonic disc at day 13-15 post fertilisation period [7] although current studies suggest fusion of two monovular embryonic disc based on analysis of several conjoint twins $[4,8]$.

The autopsy findings of parapagus conjoined twins vary greatly. With this case the foregut and its derivatives structures were all double, while the greater part of mid gut and all of the hind gut structures were singular.

Literature shows that parapagus conjoined twins usually possess two pairs of lungs of which one pair (usually the right) is hypoplastic $[9,10]$. In our case both pairs of lungs appeared normal with no obvious findings of underdevelopment. It was however observed that only the left pair of lungs had an identifiable and functional cardio-pulmonary circulatory system, thereby making them primarily responsible for the oxygenation of blood for both twins. The presence of a VSD allowed the admixture of oxygenated and deoxygenated blood and was most probably the cause of the cyanosis observed in the twins.

\section{CONCLUSION}

Majority of dicephalic parapagus conjoined twins are stillborn or survive for only a few hours [11]. The cardiopulmonary circulation in this case though complex was complete and it is our postulation that it may have been able to support the twins if the VSD could have been repaired surgically.

\section{Conflicts of Interests: None}

\section{REFERENCES}

[1]. Mutchinick OM, Luna-Muñoz L, Amar E, Bakker MK, Clementi M, Cocchi G, et al. Conjoined twins: a worldwide collaborative epidemiological study of the International Clearinghouse for Birth Defects Surveillance and Research. Am J Med Genet C Semin Med Genet. 2011; $157 \mathrm{C}$ (4):274-87.

[2]. Hari S, Sharma R, Gupta AK, Das C, Singal AK. Magnetic resonance imaging of parapagus twins. Eur J Radiol 2004; 51: 25-29.

[3]. Kaveh M, Kamrani, K, Naseri M, Danaeian M, Asadi F, Davari-Tanha F. Dicephalicparapagustribrachius conjoined twins in a triplet pregnancy: a case report. J Family Reprod Health 2014; 8:83.

[4]. Karaer A, Tanrýkulu Ý, Günep N, Çakýr E, Öztap A. Parapagusdicephalusdibrachusdipus: a case of conjoined twins. J Turk GerGynecolAssoc 2009; 10:241.

[5]. Martinez- Frias ML, Bermejo E, Mendioroz J, Rodriguez- Pinilla E, Blanco M, Egües J, Felix V, Garcia A, Huertas $H$, Nieto $C$, Lopez JA, Lopez S, Paisan L, Rosa A, Vazquez MS. Epidemiological and clinical analysis of a consecutive series of conjoined twins in Spain. J PediatrSurg 2009; 44: 811-820.

[6]. Kaufman $\mathrm{MH}$. The embryology of conjoined twins. Child NervSyst 2004; 20: 508-525.

[7]. Barth RA, Filly RA, Goldberg JD, Moore P, Silverman $\mathrm{NH}$. Conjoined twins: prenatal diagnosis and assessment of associated malformations. Radiology 1990; 177: 201-207.

[8]. Spencer R. Theoretical and analytical embryology of conjoined twins: part I: embryogenesis. 2000 ClinlAnat; 13: 36-53.

[9]. Harma, M, Harma M, Mi Z, Oksuzler C. Vaginal delivery of dicephalicparapagus conjoined twins: case report and literature review. Tohoku J Exp Med 2005; 205:179-185.

[10]. Singhal, AK, Agarwal GS, Sharma S, Gupta AK, Gupta DK. Parapagus conjoined twins: complicated anatomy precludes separation. Journal of Indian Association of Pediatric Surgeons 2006; 11:145.

[11].Groner JI, Teske DW, Teich S. Dicephalusdi pusdibrachius: an unusual case of conjoined twins. J PediatrSurg 1996; 31:1698-1700.

How to cite this article: Ato Ampomah Brown, Leonard Derkyi-Kwarteng, Emmanuel Okai, Kafui Akakpo. AUTOPSY FINDINGS OF DICEPHALIC DIBRACHIUS PARAPAGUS CONJOINED TWINS: A CASE REPORT. Int J Anat Res 2019;7(3.1):6790-6792. DOI: 10.16965/ijar.2019.231 